\title{
An empirical examination of the generalized Fisher effect using cross-sectional correlation robust tests for panel cointegration
}

\author{
Tolga Omay \\ Department of Banking and Finance, Cankaya University, Ankara, Turkey \\ Asli Yuksel \\ Department of Management, Bahcesehir University, Istanbul, Turkey \\ Aydin Yuksel ${ }^{*}$ \\ Department of Management, Isik University, Istanbul, Turkey
}

${ }^{*}$ Corresponding author: Tel.: (+90-216) 5287201; Fax: (+90-216) 7102879

E-mail: yuksel@isikun.edu.tr 


\begin{abstract}
This study examines the generalized Fisher hypothesis as applied to common stocks by using the recently proposed second generation panel cointegration tests. Unlike their predecessors, these new tests assume the existence of cross-section dependence in the data. For the sample analyzed, we report that these new tests, but not their predecessors, provide strong support for the existence of cointegration between stock and goods prices. Moreover, further analysis cannot reject the hypothesis that the cointegration relation is linear. Finally, our Fisher coefficient estimates are in the range between 0.68 and 1.27 and give support to the generalized Fisher hypothesis.
\end{abstract}

Keywords: Fisher hypothesis; Linear and Nonlinear Panel Cointegration; Cross-section dependence; Common Correlated Effects; Bootstrap

JEL Classification: E31; G10 


\section{Introduction}

The generalized Fisher hypothesis as applied to common stocks states that common stocks should provide a hedge against inflation. Early research during 1970s and 1980s report either a negative or an insignificant relation between stock returns and inflation, inconsistent with the hypothesis. These studies have, as noted by Boudoukh and Richardson (1993), all employ short-term asset returns with time horizons of one year or less. However, Kaul (1987) and Boudoukh and Richardson (1993) report that, when stock returns and inflation are evaluated over a longer time period, the Fisher hypothesis cannot be rejected. The estimated elasticity coefficient in these studies, however, is less than unity. These mixed results have been attributed to the limitations

of empirical approaches used. One major problem is that these studies throw away the long-run information contained in the data by using stock return and inflation rather than stock price and consumer price index data.

The next wave of studies take into account the potential nonstationarity and cointegration properties of stock price and consumer price indices. For example, Ely and Robinson (1997) using data from 16 industrialized countries finds that, for most of the countries analyzed, stocks do maintain their value relative to movements in overall price indexes and this conclusion generally does not depend on whether the source of the inflation shock is from the real or monetary sector. Another study, Anari and Kolari (2001) using data from six industrialized countries reports that the long-run generalized Fisher elasticities of stock prices with respect to consumer prices exceed unity and are in the range of 1.04 to 1.65 , which tend to support the Fisher effect. Similar evidence is 
provided by Luintel and Paudyal (2006) for UK industry indices. They report statistically significant elasticities in the range from 1.22 to 1.64 .

In a recent paper, Gregoriou and Kontonikas (2010) examine the long-run relationship between stock prices and goods prices using panel cointegration to utilize the dataset in the most efficient manner. One issue that has often been overlooked in empirical research is to check whether disturbances in panel data models are crosssectionally independent. In cointegration analysis, ignoring the existence of such dependence may lead to wrong inferences from unit root and cointegration tests and getting biased coefficients estimates for the long-run equation. Gregoriou and Kontonikas (2010) consider the potential cross-sectional dependence problem in their panel cointegration tests. If there is cross-sectional dependence, then the panel cointegration tests depend on nuisance parameters associated with the cross-sectional correlation properties of the data, which means that the tests no longer have a limiting normal distribution. Gregoriou and Kontonikas derive critical values in the presence of non-normality by applying a wild bootstrap simulation and find that the bootstrap test performs well and the panel cointegration tests based on the normal distribution are robust to cross sectional correlation. Their evidence supports a positive long-run relationship between goods prices and stock prices with the estimated goods price coefficient being in line with the generalized Fisher hypothesis.

This paper extends Gregoriou and Kontonikas (2010) by considering more comprehensive econometric methods. In particular, it attempts to make two contributions to the literature. First, it examines the generalized Fisher equation within a panel cointegration framework by paying special attention to the cross-section dependence issue. This is achieved by using Pedroni's fully modified OLS (FMOLS) 
estimator after augmenting its empirical specification in different ways to deal with cross-section dependence. We employ three methods for that purpose. First, we follow Westerlund (2005) and assume that the dependence can be approximated by means of common time effects. Second, as suggested by Pesaran (2006), we assume that the cross-section dependence is due to unobserved common correlated effects (CCE). Finally, we use oil prices as a proxy for the single common factor. We give evidence on the relative performance of these approaches based on a misspecification test.

The second contribution of the paper is to examine the consequences of not accounting for cross section dependence in the analysis. For that purpose, in every stage of the analysis (i.e. testing for unit root, testing for cointegration and estimation of Fisher coefficient) two sets of estimates are presented. The former ignores the crosssection dependence problem, while the latter takes it into consideration.

We report that, based on Peseran (2004) test, cross-section dependence exists in the data set. Moreover, inference about stationarity and cointegration is sensitive whether the test employed takes into account the cross-section dependence or not. Finally, the Fisher coefficients estimated by ignoring the cross-dependence problem exceed unity and are larger in magnitude than the estimates reported in Anari and Kolari (2001) and Luintel and Paudyal (2006). In contrast, estimations using Westerlund (2005) and Pesaran (2006) approaches that pass the final misspecification test, give coefficient estimates in the range between 0.68 and 1.27 in support of the generalized Fisher hypothesis.

The remainder of the paper is organized as follows. The next section discusses the econometric framework. The third section presents the data. The fourth section reports and discusses the empirical results. The last section provides the concluding remarks. 


\section{Methodology}

\subsection{Pesaran's Cross-section Dependence Test}

As discussed before, the first empirical question examined in this paper is to what extent cross-section dependence exists in the data. To explore this issue, we use crosssection dependence test of Pesaran (2004), which is based on average of pairwise correlation coefficients of the OLS residuals from the individual regressions in the panel. The test is basically an extension of Breusch and Pagan (1980) Lagrange Multiplier test. Pesaran (2004) considers the following model:

$$
y_{i, t}=\mu_{i}+\beta_{i} x_{i, t}+u_{i, t}
$$

where, on the time domain $\mathrm{t}=1,2, \ldots, \mathrm{T}$, for the cross-section units $\mathrm{i}=1,2, \ldots, \mathrm{N} . x_{i, t}$ is a $k x 1$ vector of observed time-varying regressors. The individual intercepts, $\mu_{i}$ and slope coefficients $\beta_{i}$ are defined on a compact set permitted to vary across $\mathrm{i}$. For each $\mathrm{i}$, , $u_{i, t} \sim$ iid $\left(0, \sigma_{i}^{2}\right)$ for all $\mathrm{t}$ although they could be cross-sectionally correlated. Pesaran (2004) proposes the following statistic for testing the null of zero cross equation error correlations:

$$
C D_{L M 1}=\sqrt{\frac{2 T}{N(N-1)}}\left(\sum_{i=1}^{N-1} \sum_{j=i+1}^{N} \hat{\rho}_{i, j}\right)
$$

where $e_{i, t}$ are the OLS estimates of $u_{i, t}$ and $\hat{\rho}_{i, j}$ is the sample estimate of the pair-wise correlation of the residuals: 


$$
\hat{\rho}_{i, j}=\hat{\rho}_{j, i}=\frac{\sum_{t=1}^{T} e_{i, t} e_{j, t}}{\left(\sum_{t=1}^{T} e_{i, t}^{2}\right)^{1 / 2}\left(\sum_{t=1}^{T} e_{j, t}^{2}\right)^{1 / 2}}
$$

The test is especially attractive when the number of individual units in the panel is large since it is known that Breusch and Pagan's LM test is likely to exhibit substantial size distortions in this case. In the analysis, Breusch and Pagan LM test and its scaled versions are also reported for comparison purposes. These are:

$$
\begin{aligned}
& C D_{L M 2}=T \cdot\left(\sum_{i=1}^{N-1} \sum_{j=i+1}^{N} \hat{\rho}_{i, j}^{2}\right) \\
& C D_{L M 3}=\sqrt{\frac{1}{N(N-1)}}\left(\sum_{i=1}^{N-1} \sum_{j=i+1}^{N}\left(T \cdot \hat{\rho}_{i, j}^{2}-1\right)\right)
\end{aligned}
$$

After giving evidence on the extent of cross-section dependence in the data, the analysis follows the usual steps for panel cointegration analysis. Since our aim is to assess the importance of ignoring cross-section dependence on the results, panel unit root tests, panel cointegration tests and the estimation of long-run coefficient in the generalized Fisher equation are performed separately with and without assuming crosssection dependence.

\subsection{Panel Unit Root Tests}

As the benchmark that assumes no cross-section dependence, we first compute the IPS test statistics (Im et al., 2003), which is based on the well-known Dickey-Fuller procedure. This test combines information from the time series dimension with that from the cross section dimension, such that fewer time observations are required for the test 
to have power. IPS considers a stochastic process, $y_{i t}$, which is generated by the firstorder autoregressive process with individual effects and no time trend:

$$
y_{i, t}=\left(1-\varphi_{i}\right) \mu_{i}+\varphi_{i} y_{i, t-1}+u_{i t} \quad \text { where } \mathrm{i}=1, \ldots, \mathrm{N} \text { and } \mathrm{t}=1, \ldots, \mathrm{T}
$$

In this case the relevant Dickey-Fuller (1979) regression for each cross-section is:

$$
\Delta y_{i, t}=\alpha_{i}+\beta_{i} y_{i, t-1}+u_{i t} \text { where } \Delta y_{i, t}=y_{i, t}-y_{i, t-1}, \alpha_{i}=\left(1-\varphi_{i}\right) \mu_{i} \text { and } \beta_{i}=-\left(1-\varphi_{i}\right)
$$

The unit root hypothesis of interest, $\varphi_{i}=1$, can now be expressed as

$$
H_{0}: \beta_{i}=0 \quad \text { for all } \mathrm{i}
$$

against the possibly heterogeneous alternatives,

$$
H_{1}: \beta_{i}<0 \quad \text { for some i }
$$

After estimating the separate Dickey-Fuller regressions, $t$ statistics are calculated for each cross-section:

$$
t_{i T}=\frac{\hat{\beta}_{i T}\left(y_{i,-1}^{\prime} M_{\tau} y_{i,-1}\right)^{1 / 2}}{\hat{\sigma}_{i T}}=\frac{\Delta y_{i}^{\prime} M_{\tau} y_{i,-1}}{\hat{\sigma}_{i T}\left(y_{i,-1}^{\prime} M_{\tau} y_{i,-1}\right)^{1 / 2}}
$$

where $\hat{\beta}_{i T}$ is the OLS estimator of $\beta_{i}$ and

$$
\begin{aligned}
& \Delta y_{i}=\left(\Delta y_{i, 1}, \Delta y_{i, 2}, . ., \Delta y_{i, T}\right)^{\prime}, \quad y_{i,-1}=\left(y_{i, 0}, y_{i, 1}, . ., y_{i, T-1}\right)^{\prime}, \quad \tau_{T}=(1,1 \ldots, 1)^{\prime}, \quad M_{\tau}=I_{T}-\tau_{T}\left(\tau_{T}^{\prime} \tau_{T}\right)^{-1} \tau_{T}^{\prime} \\
& \hat{\sigma}_{i, T}=\frac{\Delta y_{i}^{\prime} M_{x_{i}} \Delta y_{i}}{T-2} \quad M_{x_{i}}=I_{T}-x_{i}\left(x_{i}^{\prime} x_{i}\right)^{-1} x_{i}^{\prime} \text { and } x_{i}=\left(\tau_{T}, y_{i,-1}\right)
\end{aligned}
$$

The average of these t-statistics forms the IPS statistics, $\bar{t}_{N T}$ : 


$$
\bar{t}_{N T}=\frac{1}{N} \sum_{i=1}^{N} t_{i, T}\left(\beta_{i}\right)
$$

To deal with the potential cross-section dependence problem, testing for unit root is repeated, this time using Pesaran's (2007) cross-sectionally augmented IPS (CIPS) test. A brief description of the CIPS test is as follows.

Let $y_{i, t}$ be the observation on the $i^{t h}$ cross-section unit at time $t$ and suppose that it is generated according to the simple dynamic linear heterogeneous panel data model as given in (5). In the simple case where $u_{i, t}$ is serially uncorrelated, Pesaran assumes that the error term, $u_{i, t}$, has the single-factor structure:

$$
u_{i, t}=\gamma_{i} f_{t}+\varepsilon_{i, t}
$$

where $f_{t}$ is the unobserved common effect, and $\varepsilon_{i, t}$ is the individual-specific (idiosyncratic) error.

Then following the line of reasoning in Pesaran $(2006,2007)$, the common factor $f_{t}$ can be proxied by the cross section mean of $\quad y_{i, t}$, namely $\quad \bar{y}_{t}=\frac{1}{N} \sum_{j=1}^{N} y_{j, t}$, and its lagged value(s), $\bar{y}_{t-1}, \bar{y}_{t-2}, \ldots$ for $\mathrm{N}$ sufficiently large. Pesaran $(2006,2007)$ confirms that cross sectional dependence can be accounted for by augmenting the standard DickeyFuller regression given by equation (6) with the cross section averages of lagged levels and first differences of the individual series.

$$
\Delta y_{i, t}=a_{i}+b_{i} y_{i, t-1}+c_{i} \bar{y}_{t-1}+d_{i} \Delta \bar{y}_{t}+e_{i, t}
$$


We shall therefore base our test of the unit root hypothesis, on the t-ratio of the OLS estimate of $b_{i}\left(\hat{b}_{i}\right)$ in equation (10). Denoting this t-ratio by $t_{i}(N, T)$ we have

$$
C A D F_{i}=t_{i}(N, T)=\frac{\Delta y_{i}^{\prime} \bar{M}_{w} y_{i,-1}}{\hat{\sigma}_{i}\left(y_{i,-1}^{\prime} \bar{M}_{w} y_{i-1}\right)^{1 / 2}}
$$

where

$$
\begin{gathered}
\Delta y_{i}=\left(\Delta y_{i, 1}, \Delta y_{i, 2}, . ., \Delta y_{i, T}\right)^{\prime}, \quad y_{i,-1}=\left(y_{i, 0}, y_{i, 1}, . ., y_{i, T-1}\right)^{\prime}, \quad \tau_{T}=(1,1 \ldots, 1)^{\prime}, \\
M_{w}=I_{T}-\bar{W}\left(\bar{W} \bar{W}^{\prime}\right)^{-1} \bar{W}^{\prime}, \quad \bar{W}=\left(\tau, \Delta \bar{y}, \bar{y}_{-1}\right) \\
\Delta \bar{y}=\left(\Delta \bar{y}_{1}, \Delta \bar{y}_{2}, \ldots \Delta \bar{y}_{T}\right)^{\prime}, \quad \bar{y}_{-1}=\left(\bar{y}_{0}, \bar{y}_{1}, \ldots \bar{y}_{T-1}\right)^{\prime}
\end{gathered}
$$

$\hat{\sigma}_{i}^{2}=\frac{\Delta y_{i}^{\prime} M_{i, w} \Delta y_{i}}{T-4} \quad M_{i, w}=I_{T}-G_{i}\left(G_{i}^{\prime} G_{i}\right)^{-1} G_{i}^{\prime} \quad$ and $\quad G_{i}=\left(\bar{W}, y_{i,-1}\right)$

The simple average of the individual cross-sectionally augmented Dickey-Fuller statistics $\left(\mathrm{CADF}_{\mathrm{i}}\right)$ forms the cross-sectionally augmented IPS (CIPS) test statistic. Pesaran (2007) illustrates that the individual CADFs and the corresponding panel statistic (CIPS) have non-normal distributions, so their critical values for different $\mathrm{N}$ and T are obtained by Monte Carlo simulations. Pesaran (2007) gives critical values of CIPS in Tables II (a)-II(c).

\subsection{Linear Panel Cointegration Tests}

As the benchmark that assumes no cross-section dependence, we first compute the residual-based tests of Pedroni (1999) for the null of no cointegration. Pedroni allows the slope coefficients in the cointegration vector to vary across individual members of the panel. He considers the use of seven residual-based panel cointegration statistics, four based on pooling the data along the within-dimension (denoted 'panel cointegration 
statistics') and three based on pooling along the between-dimension (denoted 'group mean cointegration statistics'). Panel statistics differ from group statistics regarding the specification of the alternative hypothesis. The panel cointegration statistics impose a common coefficient under the alternative hypothesis and the group mean cointegration statistics allow for heterogeneous coefficients under the alternative hypothesis. In order to test the null of no cointegration, the mean and variance adjustment terms reported in Pedroni (1999) are used to compute the values of these test statistics. These are then compared to the appropriate tails of the normal distribution.

To deal with the potential cross-section dependence problem in panel cointegration tests, we use two alternative ways. First, following Ucar and Omay (2009), we apply sieve bootstrap method to the residuals $u_{i t}$ in the following panel regression model:

$$
y_{i, t}=\gamma_{i}+\theta_{i} x_{i, t}+u_{i, t} \quad \text { where } \mathrm{i}=1, \ldots, \mathrm{N} \text { and } \mathrm{t}=1, \ldots, \mathrm{T}
$$

We obtain estimates of residuals by using OLS estimates of $\gamma_{i}$ and $\theta_{i}$.

$$
\hat{u}_{i, t}=y_{i, t}-\hat{\gamma}_{i}+\hat{\theta}_{i} x_{i, t}
$$

Using the bootstrap algorithm, explained in Ucar and Omay (2009) in detail, we generate bootstrap samples of $\hat{u}_{i, t}$. The bootstrap statistics of $t_{i T}^{*}$, are computed for each replication as discussed in panel unit root testing section by using equations (5) to (7) . For each replication, we form the IPS statistics by taking the average of these $t_{i T}^{*}$ statistics. The bootstrap empirical distribution of IPS statistics, generated by employing 2,000 replications, are used to obtain the p-value.

Second, we use Banerjee and Carrion-Silvestre (2011) common correlated effects estimator. Banerjee and Carrion-Silvestre show that consistent estimation of the long- 
run average parameter is possible once they control for cross-section dependence using cross-section averages in the spirit of the common correlated effects approach in Pesaran (2006), Holly, Pesaran and Yamagata (2010) and Kapetanios, Pesaran and Yamagata (2011). They specify the following cross-section augmented regression:

$$
y_{i, t}=D_{i, t}+x_{i, t}^{\prime} \beta_{i}+\bar{z}_{t} \varphi_{i}+u_{i, t}
$$

where $\bar{z}_{t}=\left(\bar{y}_{t} \bar{x}_{t}\right)$ is $1 \times 2$ vector of cross-section averages of dependent and independent variables and $D_{i, t}$ equals $0, \mu_{i}$ or $\delta_{i}+\delta_{i} t$ depending on whether the model has no intercept, intercept only and both intercept and time trend.

In the first stage, the pooled CCE estimator (PCCE) in Pesaran (2006) is used to estimate the parameters:

$$
\hat{\beta}_{P C C E}=\left(\sum_{i=1}^{N} x_{i}^{\prime} \bar{M} x_{i}\right)^{-1}\left(\sum_{i=1}^{N} x_{i}^{\prime} \bar{M} y_{i}\right)
$$

In the second stage the estimated PCCE parameters are used to define the variable:

$$
\tilde{y}_{i, t}=y_{i, t}-x_{i, t}^{\prime} \hat{\beta}_{P C C E}
$$

for which the following model is estimated using the OLS estimation procedure:

$$
\tilde{y}_{i, t}=D_{i, t}+e_{i, t}
$$

and the OLS residuals are then computed as $\hat{e}_{i, t}=\tilde{y}_{i, t}-\hat{D}_{i, t}$. In the last stage, the null hypothesis of no cointegration is tested analyzing the order of integration of $\hat{e}_{i, t}$ through the application of the cross-section augmented Dickey-Fuller cointegration statistic. 
Banerjee and Carrion-Silvestre give the critical values of their test statistic in Tables 3 and 4.

\subsection{Non-Linear Panel Cointegration Test}

To further examine whether the cointegration relationship is non-linear, we employ Omay et al. (2012) nonlinear panel cointegration test. Below we give a brief description of this test.

Consider following panel regression model:

$$
y_{i, t}=\alpha_{i}+\beta_{i} x_{i, t}+u_{i, t}
$$

where $y_{i, t}$ and $x_{i, t}$ denote observable $I(1)$ variables, $\beta=\left(\beta_{1}, \ldots, \beta_{m}\right)$ are parameters to be estimated, and $u_{i, t}$ is the error term. $y_{i, t}$ is scalar, and $\mathbf{x}_{i, t}=\left(x_{1, t}, x_{2, t}, \ldots, x_{m, t}\right)$ is an ( $m \times 1)$ vector and finally $\alpha_{i}$ is fixed effect (heterogeneous intercept). We assume that an $(n \times 1)$ vector $z_{i, t}^{\prime} \equiv\left(y_{i, t}, x_{i, t}\right)$ is generated as $z_{i, t}=z_{i, t-1}+\varepsilon_{i, t}$, where $e_{i, t}$ are i.i.d. with mean zero, positive definite variance-covariance matrix $\Sigma$, and $E\left|\varepsilon_{i, t}\right|^{s}<\infty$ for some $s>4$.

If the error term $u_{i, t}$ in regression (18) is stationary, then vector $\mathbf{z}_{i, t}$ is said to be cointegrated, and $u_{i, t}$ is called equilibrium error (Engle and Granger, 1987). We assume that $u_{i, t}$ can be modeled using following nonlinear model:

$$
u_{i, t}=u_{i, t-1}+\phi_{i} u_{i, t-1} F\left(u_{i, t-1} ; \theta_{i}\right)+\xi_{i, t}
$$


where $\xi_{i, t-1}$ is a zero mean error and $F\left(u_{i, t-1} ; \theta_{i}\right)$ is a smooth transition function of $u_{i, t-1}$. Note that by imposing $F\left(u_{i, t-1} ; \theta_{i}\right)=0$ or $F\left(u_{i, t-1} ; \theta_{i}\right)=-\gamma_{i} \mu_{i}$ where $\mu_{i}$ is vector of level parameters, one obtains conventional linear cointegration equation (e.g., Kapetanois et al., 2006). Following earlier literature on nonlinear cointegration (e.g., Kapetanois et al., 2003, 2006; Ucar and Omay, 2009, Maki, 2010) we assume that the transition function $F\left(u_{i, t-1} ; \theta_{i}\right)$ is of the exponential form ${ }^{1}$ :

$$
F\left(u_{i, t-1} ; \theta_{i}\right)=1-\exp \left\{-\theta_{i} u_{i, t-1}^{2}\right\}
$$

Here it is further assumed that $u_{i, t}$ is a mean zero stochastic process and that $\theta_{i} \geq 0$. The transition function $F\left(u_{i, t-1} ; \theta_{i}\right)$ is bounded between zero and one, and is symmetrically U-shaped around zero. The parameter $\theta_{i}$ determines the speed of the transition between the two extreme values of the transition function ${ }^{2} F\left(u_{i, t-1} ; \theta_{i}\right)$. The exponential transition function has a nice property in that it allows for adjustment to the long-run equilibrium depending on the size of the disequilibrium.

Substituting (20) in (19) and reparameterizing the resultant equation, we obtain following regression model:

$$
\Delta u_{i, t}=\varphi_{i} u_{i, t-1}+\psi_{i} u_{i, t-1}\left[1-\exp \left\{-\theta u_{i, t-1}^{2}\right\}\right]+\varepsilon_{i, t}
$$

\footnotetext{
${ }^{1}$ Kapetanois et al. $(2003,2006)$ show that both second-order logistic and exponential functions give rise to the same auxiliary regression for testing the cointegration.

${ }^{2}$ For a detailed discussion of smooth transition regression models and properties of transition functions, see, for example, Granger and Teräsvirta (1993) and Teräsvirta (1994).
} 
If $\theta_{i} \geq 0$, then it determines the speed of mean reversion. If $\varphi_{i} \geq 0$, this process may exhibit unit root or explosive behaviour for small values of $u_{i, t-1}^{2}$. However, if the deviations from the equilibrium are sufficiently large (i.e., for large values of $u_{i, t-1}^{2}$ ), it has stable dynamics, and as a result, is geometrically ergodic provided that $\varphi_{i}+\psi_{i}<0^{3}$.

Imposing $\varphi_{i}=0$ (implying that $u_{i, t}$ follows a unit root process in the middle regime) and further allowing for possible serial correlation of the error term in (4) we obtain the following regression model:

$$
\Delta u_{i, t}=\varphi_{i} u_{i, t-1}+\psi_{i} u_{i, t-1}\left[1-\exp \left\{-\theta_{i} u_{i, t-1}^{2}\right\}\right]+\sum_{j=1}^{p} \rho_{i j} \Delta u_{i, t-j}+\varepsilon_{i, t}
$$

Test of cointegration can be based on the specific parameter $\theta_{i}$, which is zero under the null hypothesis of no cointegration, and positive under the alternative hypothesis. However, direct testing of the null hypothesis is not feasible, since $y_{i}$ is not identified under the null. To overcome this problem, following Luukkonen et al. (1988), one may replace the transition function $F\left(u_{i, t-1} ; \theta_{i}\right)=1-\exp \left\{-\theta_{i} u_{i, t-1}^{2}\right\}$ with its first-order Taylor approximation under the null, which results in the following auxiliary regression model:

$$
\Delta u_{i, t}=\delta_{i} u_{i, t-1}^{3}+\sum_{j=1}^{p} \rho_{i j} \Delta u_{i, t-j}+e_{i, t}
$$

where $e_{i, t}$ comprises the original shocks $\varepsilon_{i, t}$ in equation (22) as well as the error term resulting from Taylor approximation. Note that we allow for different lag order $p_{i}$ for

\footnotetext{
${ }^{3}$ For ergodicity of such nonlinear processes, see Kapetanois et al. (2003) and Ucar and Omay (2009).
} 
each entity in regression equation (23). Now, the null hypothesis of no cointegration and the alternative can be formulated as:

$$
\begin{array}{ll}
H_{0}: \delta_{i}=0, & \text { for all } \mathrm{i}, \quad \text { (no cointegration) } \\
H_{0}: \delta_{i}<0, & \text { for some } \mathrm{i},(\text { Non-linear ) }
\end{array}
$$

In empirical application, one may select the number of augmentation terms in the auxiliary regression (23) using any convenient lag selection method. Following Ucar and Omay (2009), the cointegration test can be constructed by standardizing the average of individual cointegration test statistics across the whole panel. The cointegration test for the $\mathrm{i}^{\text {th }}$ individual is the $\mathrm{t}$-statistics for testing $\delta_{i}=0$ (as in Kapetanois et al., 2003 and Ucar and Omay, 2009) in equation (23) defined by:

$$
t_{i, N L}=\frac{\Delta u_{i}^{\prime} M_{t} u_{i,-1}^{3}}{\hat{\sigma}_{\hat{\imath}, N L}\left(u_{i,-1}^{\prime} M_{t} u_{i,-1}\right)^{3 / 2}}
$$

where $\quad \hat{\sigma}_{i, N L}^{2}$ is the consistent estimator such that $\hat{\sigma}_{i, N L}^{2}=\Delta u_{i}^{\prime} M_{t} u_{i} /(T-1)$, $M_{t}=I_{T}-\tau_{T}\left(\tau_{T}^{\prime} \tau_{T}\right)^{-1} \tau_{T}^{\prime}$ with $\Delta u_{i}=\left(\Delta u_{i-1}, \Delta u_{i-2}, \ldots \Delta u_{i-T}\right)^{\prime}$ and $\tau_{T}=(1,1, \ldots, 1)$

Furthermore, when the invariance property and the existence of moments are satisfied, the usual normalization of $\bar{t}_{N L}$ statistic is obtained as follows:

$$
\overline{\mathrm{Z}}_{N L}=\frac{\sqrt{N}\left(\bar{t}_{N L}-E\left(t_{i, N L}\right)\right)}{\sqrt{\operatorname{var}\left(t_{i, N L}\right)}}
$$


where $\bar{t}_{N L}=N^{-1} \sum_{i=1}^{N} t_{N L}$, and $E\left(t_{i, N L}\right)$ and $\operatorname{var}\left(t_{i, N L}\right)$ are expected value and variance of the $t_{i, N L}$ statistic given in (24).

We apply Ucar and Omay (2009) bootstrap procedure with 2,000 replications to obtain empirical distribution of the test statistic.

\subsection{Estimation of Fisher Coefficient}

Following the cointegration tests, the long-run elasticity of stock prices to goods prices is estimated using the Pedroni (2000) fully modified OLS (FMOLS) estimator. Pedroni estimator deals with complications introduced by the presence of parameter heterogeneity in the dynamics and fixed effects across individual members. The former is modeled by allowing the associated serial correlation properties of the error processes to vary across individual members of the panel. The latter is modeled by including individual specific intercepts. Pedroni's approach is similar in spirit to Phillips and Hansen (1990)'s semi-parametric correction to the OLS estimator, which eliminates the second order bias induced by the endogeneity of the regressors. Pedroni applies the same principle to the panel OLS estimator. The key difference in constructing the estimator for the panel data case is to account for the heterogeneity that is present in the fixed effects as well as in the short run dynamics.

Pedroni employs the following system of equations:

$$
\begin{aligned}
& y_{i, t}=\mu_{i}+\beta^{\prime} x_{i, t}+u_{i, t} \\
& x_{i, t}=x_{i, t-1}+\varepsilon_{i, t}
\end{aligned}
$$

where $\xi_{\mathrm{i}, \mathrm{t}}=\left[\mathrm{u}_{\mathrm{i}, \mathrm{t}} \varepsilon_{\mathrm{i}, \mathrm{t}}\right]$ is stationary with covariance matrix $\Omega_{\mathrm{i}}$. 
Pedroni panel FMOLS estimator, $\hat{\beta}$ is:

$$
\hat{\beta}-\beta=\left(\sum_{i=1}^{N} \hat{L}_{22 i}^{-2} \sum_{t=1}^{T}\left(x_{i, t}-\bar{x}_{i}\right)^{2}\right)^{-1} \sum_{i=1}^{N} \hat{L}_{11}^{-1} \hat{L}_{22 i}^{-1}\left(\sum_{t=1}^{T}\left(x_{i, t}-\bar{x}_{i}\right) u_{i, t}^{*}-T \hat{\gamma}_{i}\right)
$$

where

$$
u_{i t}^{*}=u_{i, t}-\frac{\hat{L}_{21 i}}{\hat{L}_{22 i}} \Delta x_{i, t} \quad \hat{\gamma}_{i}=\hat{\Gamma}_{21 i}+\hat{\Omega}_{21 i}^{0}-\frac{\hat{L}_{21 i}}{\hat{L}_{22 i}}\left(\hat{\Gamma}_{22 i}+\hat{\Omega}_{22 i}^{0}\right)
$$

$\hat{L}_{i}$ is a lower triangular decomposition of $\hat{\Omega}_{i}$ and $\Gamma_{i}$ is a weighted sum of autocovariances.

Pedroni's FMOLS estimator does not take into account the potential cross-section dependence in panels. However, it can still be used after augmenting its empirical specification in different ways to deal with cross-section dependence. We will use three methods for that purpose. First, we follow Westerlund (2005) and assume that the dependence can be approximated by means of common time effects. We, therefore, use cross-section demeaned data with the original empirical specification, which is tantamount to the inclusion of a common time effect in the cointegrating long-run relation. An advantage of this approach is that subtracting the cross-sectional average may be quite effective even against very general forms of cross-sectional correlation structures.

Second, we follow Pesaran (2006) and assume that cross-section dependence is due to unobserved common factors. This method, known as Common Correlated Effects (CCE), approximates the linear combinations of the unobserved factors by cross 
section averages of the dependent and explanatory variables and augments the model with these cross section averages. An advantage of this approach is that it yields consistent estimates also when the regressors are correlated with the factors. Third, we use oil prices as a proxy for the single common factor. In other words, we augment the empirical specification by adding oil prices.

Finally, once the long-run elasticity of stock prices to goods prices is estimated using different approaches, we apply once again the Pesaran (2004) cross section dependence test to the residuals to check whether cross-section dependence problem has been dealt to a satisfactory level or not.

\section{Data}

Monthly data for goods prices, measured by the national consumer price index , nominal stock prices, measured by the national stock price index and oil prices, measured by the price of a barrel of Brent crude oil are collected from Datastream. Considering the tradeoff between the number of countries with available data and the time period used, we choose January 1997 as the starting date of our sample period to have data for a reasonably large number of countries. To eliminate the impact of global financial crisis of 2008 on our analysis, we choose December 2007 as the ending date

of the sample period. This results in a sample of 52 countries with 132 monthly observations. As discussed in Gregoriou and Kontonikas (2010), during this time period inflationary pressures were largely brought under control.

Our analysis will be conducted not only for the full sample, but also for different subgroups of countries. We classify the sample countries as developed, emerging and 
other based on Morgan Stanley Capital International (MSCl) classification of markets. ${ }^{4}$ Based on this classification, we have 21 developed (Austria, Belgium, Canada, Denmark, Finland, France, Germany, Hong Kong, Ireland, Italy, Japan, Luxembourg, Netherlands, Norway, Portugal, Singapore, Spain, Sweden, Switzerland, United Kingdom, and United States), 19 emerging (Argentina, Brazil, Chile, China, Czech Republic, Egypt, Hungary, India, Israel, Jordan, Malaysia, Morocco, Philippines, Poland, Russian Federation, South Africa, Taiwan, Thailand, and Turkey) and 12 other (Croatia, Estonia, Iran, Jamaica, Latvia, Mauritius, Slovakia, Sri Lanka, Saudi Arabia, Trinidad and Tobago, Venezuela, and Zambia) markets in our data set.

We also classify countries based on the average level of realized inflation during the sample period. We use two classifications for that purpose. The first classification (hereafter INF1) divides countries into two groups. Depending on whether a country's average inflation level is above or below the sample median, a country is classified as either high inflation (INF1 H) or low inflation (INF1 L) country. Each of these two groups contain 26 countries. The second classification (hereafter INF2) divides countries into three groups. These are high inflation (INF2 H), moderate inflation (INF2 M) and low inflation (INF2 L) groups. ${ }^{5}$ These three groups contain, 12, 26 and 14 countries, respectively. The use of subgroups will allow us to provide additional evidence on the robustness of the long-run relation between stock prices and goods prices.

During the sample period, the growth rate of nominal stock prices exceeded that of goods prices in all countries, with the exception of Latvia, Malaysia, Philippines,

\footnotetext{
${ }^{4}$ Other countries group contains the sample countries that are neither developed nor emerging based on MSCI classification.

${ }^{5}$ INF2 $\mathrm{H}$ group contains countries in which average monthly inflation exceed $0.5 \%$, while INF2 $\mathrm{L}$ group contains countries in which average monthly inflation is below $0.16 \%$. INF2 M group contains the remaining countries.
} 
Thailand, and Venezuela. Average monthly inflation ranges from $-0.015 \%$ in Hong Kong to $2.539 \%$ in Turkey. Average monthly stock returns range from $0.069 \%$ in Philippines to $2.912 \%$ in Russian Federation. The average monthly growth rate of goods prices across our sample countries is $0.412 \%$ while the corresponding nominal stock price growth rate is $0.94 \%$, indicating a positive real stock price growth of $0.530 \%$.

\section{Empirical Analysis}

We start the analysis by examining the extent of cross-section dependence in the data by using Pesaran (2004) test. For comparison purposes, we also employ Breusch and Pagan (1980) Lagrange Multiplier test and its scaled version. Table 1 reports the results for the whole sample and for every subgroup. All the three versions of the test statistic are statistically significant at better than the 0.001 level for the whole sample and for all the subgroups. This gives support for the motivation of the paper, namely the crosssection dependence should not be ignored in the examination of the Fisher hypothesis.

\section{Insert Table 1 here}

Before testing for the cointegration relationship, stochastic properties of consumer price index and stock prices are examined by computing panel unit root tests. We first ignore the cross-dependence problem. Table 2 displays, for all groups, the IPS test statistic, $\bar{t}_{N T}$. In each case, the table reports $\bar{t}_{N T}$ statistic for two specifications. The first specification contains intercept as the only deterministic element, while the second includes both intercept and a linear time trend. The test statistics reveal that for all groups consumer price index and stock prices are nonstationary in level and stationary 
in their first difference. Thus, there may exist a cointegration relationship between these variables.

\section{Insert Table 2 here}

Testing for unit root is repeated, this time using Pesaran's (2007) cross-sectionally augmented IPS (CIPS) test, which takes into account cross-section dependence. The test statistics, as shown in Table 3, indicate that for all groups, except developed countries, consumer price index and stock prices are nonstationary in level and stationary in their first difference. Thus, panel unit root testing for developed countries is sensitive whether or not one allows for cross-section dependence. Since our aim is to document to what extent one can make incorrect inferences from the data if crosssection dependence is not modeled, we will not drop developed countries from the sample in the rest of analysis.

\section{Insert Table 3 here}

The analysis then continues with the panel cointegration tests. As the benchmark that assumes no cross-section dependency, we first compute the seven residual-based tests of Pedroni (1999). Table 4 reports the results. Pedroni tests do not give support for the existence of cointegration neither for the whole sample nor for any of the subgroups. Replacing stock prices with goods prices as the dependent variable results into finding no-cointegration between the two variables as well. ${ }^{6}$

\section{Insert Table 4 here}

\footnotetext{
${ }^{6}$ Results are not reported, but available upon request.
} 
Given the benchmark results in Table 4, we now employ panel cointegration tests that take into consideration cross-section dependence in data. Table 5 displays the results of three different tests. The second column of the table displays the computed values of Banerjee and Carrion-Silvestre (2011) common correlated effects estimator. The third column of the table displays the Ucar and Omay (2009) IPS statistic and p values obtained from bootstrap empirical distribution of the IPS statistics. To further examine whether the cointegration relationship is non-linear, we employ Omay et al. (2012) nonlinear panel cointegration test. The fourth column of the table reports these nonlinear panel cointegration test statistics and corresponding $p$ values obtained from bootstrap empirical distribution. Banerjee and Carrion-Silvestre test indicates that stock prices and goods prices are cointegrated for the whole sample as well as for all subgroups, except the Others, INF1 H and INF2 H subgroups. In contrast, Ucar and Omay (2009) bootstrap procedure does not provide support for the existence of cointegration neither for the whole sample nor for any of the subgroups. Thus, based on the results in Table 5, the comparison of two t popular methods to deal with crosssection dependence, namely CCE and bootstrap methods, we conclude that the CCE estimator better suits the data. Finally, the statistical insignificance of Omay et al. (2012) nonlinear panel cointegration test statistics for all the groups, indicates that the hypothesis that there exists nonlinear cointegration relationship between stock prices and goods prices finds no support in the data.

\section{Insert Table 5 here}

Based on the positive evidence in Table 5 for the existence of cointegration, we proceed to fully evaluate the prediction of long-run hedging inherent in the generalized 
Fisher hypothesis and estimate the long-run elasticity of stock prices to goods prices using the Pedroni (2000) fully modified OLS heterogeneous cointegrated panel methodology. Table 6 reports fully modified OLS estimates for the whole sample and for all the eight subgroups. The first row of Table 6 reports the Fisher coefficients for the case where the cross-section dependence problem is ignored. Rows 2-4 reports the Pedroni fully modified OLS estimates obtained after augmenting its empirical specification in different ways to deal with cross-section dependence. The second row shows the coefficient estimates obtained under the assumption that cross-section dependence can be approximated by means of common time effects as suggested by Westerlund (2005). The third row show the coefficient estimates obtained under the assumption that cross-section dependence is due to correlated unobserved common effects as suggested by Pesaran (2006). The fourth row reports the Fisher coefficient estimates where the empirical specification is augmented by oil prices, which proxies the single common factor causing the cross-sectional dependence.

For the case when the cross-sectional dependence problem is ignored, the reported Fisher coefficient is significantly different from zero at the $1 \%$ level for the whole sample as well as for all the subgroups. For the whole sample, the Fisher coefficient equals 2.44 , and for the subgroups it ranges from 1.70 to 2.74 . This finding that the elasticities of stock prices with respect to consumer prices exceed unity is consistent with the findings of prior literature that take the cointegration relation into account. For example, Anari and Kolari (2001) using data from six industrial countries find that Fisher elasticities exceed unity and range from 1.04 to 1.65. Moreover, Luintel and Paudyal (2006) using UK aggregate and industry data find that for the aggregate market index 
(1.197) as well for six of seven industry groups examined Fisher coefficient exceeds unity (ranges from 1.22 to 1.64 ).

Given the benchmark case, we now consider estimation results for the three methods used to deal with the cross-dependence problem. As shown in the second row of the table, using the Westerlund method, gives significant coefficient estimate for the whole sample as well as for six of the eight subgroups. The third row of the table shows the coefficient estimates, when the empirical specification is augmented by the cross section mean of the dependent variable and its lagged values. The coefficient estimates are significant for the whole sample as well as for four subgroups. Finally, the fourth row shows the coefficient estimates, when the empirical specification is augmented by oil prices. The coefficient estimates are significant only for two subgroups. It is noteworthy that for the three methods used to deal with the cross-section dependence problem, the coefficient estimates are smaller than those for the benchmark case that ignores the problem.

\section{Insert Table 6 here}

The wide range of significant Fisher coefficient estimates in Table 6 point to the need for a misspecification test to check to what extent different methods used in estimation solve the cross section dependence problem. It is well known that neglecting cross-section dependence when it exists in the data can lead to biased estimates. For this purpose, we apply once again the Pesaran (2004) cross section dependence test to the FMOLS residuals. Table 7 reports $C D_{L M 1}$ test statistics and the corresponding $p$ values. The null hypothesis of no cross section dependence cannot be rejected in only three cases. These are Westerlund (2005) common time effects estimations using the 
whole sample and the subgroup containing countries with moderate level of inflation (INF2 M) and Pesaran (2006) CCE estimation using the subgroup containing countries with low level of inflation (INF2 L). Therefore, the coefficient estimates corresponding to these estimations are reliable estimates to evaluate the empirical validity of the generalized Fisher hypothesis. These three coefficients are in the range between 0.68 and 1.27 .

\section{Insert Table 7 here}

\section{Conclusions}

We examine the generalized Fisher hypothesis within a panel cointegration framework by paying special attention to the cross-sectional dependence issue. Not only do we aim to make sure that we get unbiased estimates for the elasticity of stock prices with respect to consumer prices, but we also want to measure to what extent the problem of not accounting for cross section dependence in the analysis affects the findings. We employ three different methods to alleviate the cross-section dependence problem.

The results reveal the following: First, the cross-section dependence problem should not be ignored in examining the generalized Fisher hypothesis within a panel cointegration framework. This problem exists in the data and has nontrivial impact on the results. Second, none of the methods employed completely eliminates the crosssection dependence. More specifically, our diagnostic check shows that using oil prices as a proxy for the single common factor causing the cross-sectional dependence shows a weak performance. The other two methods, namely Westerlund (2005) common time effects estimation and Pesaran (2006) CCE estimation, show good performance only for 
specific subgroups. For our sample, the Westerlund type treatment shows superior performance. However, this is most likely to be data specific. Pesaran (2006) argues that Westerlund (2005) type treatment is useful in dealing with weak cross- section dependence. Third, the subset of our Fisher coefficient estimates, which our diagnostic check indicates to be reliable, range between 0.68 and 1.27 . Thus, we conclude that the generalized Fisher hypothesis finds support in our data set. Finally, despite our use of more detailed tests, our findings confirm the overall conclusions in Gregoriou and Kontonikas (2010). 


\section{References}

Amihud, Y., 1996. Unexpected inflation and stock returns revised-Evidence from Israel. Journal of Money Credit and Banking 28, 22-33.

Anari, A., Kolari, J., 2001. Stock prices and inflation. Journal of Financial Research 24, 587602.

Banerjee, A., Carrion-Silvestre, JL., 2011, Testing for panel cointegration using common correlated effects estimators. Discussion Paper. University of Birmingham, Birmingham.

Boudoukh, J., Richardson, M., Whitelaw, R.W., 1994, Industry returns and Fisher effect. Journal of Finance 44, 1595-1615.

Breusch, T. S., Pagan, A.R., 1980. The Lagrange multiplier test and its applications to model specification in econometrics. Review of Economic Studies 47, 239-253.

Dickey, D.A., Fuller, W.A., 1979. Distribution of the estimators for autoregressive time series with a unit root. Journal of the American Statistical Association 74, 427-431.

Ely, D. P., Robinson, K. J., 1997. Are stocks a hedge against inflation? International evidence using a long-run approach. Journal of International Money and Finance 16, 141-167.

Engle, R.F., Granger, C.W.J., 1987. Cointegration and error correction: Representation, estimation, and testing. Econometrica 55, 251-276.

Granger, C.W.J., Teräsvirta, T., 1993. Modelling nonlinear economic relationships. Advanced Texts in Econometrics. Oxford University Press, New York.

Gregoriou, A., Kontonikas, A., 2010. The long-run relationship between stock prices and goods prices: New evidence from panel cointegration. Journal of International Financial Markets, Institutions and Money 20, 166-176.

Holly, S., Pesaran, M. H., Yamagata, T., 2010. A spatio-temporal model of house prices in the USA, Journal of Econometrics 158, 160-173.

Im K.S., Pesaran, M.H., Shin, Y., 2003. Testing for unit roots in heterogeneous panels. Journal of Econometrics 115, 53-74.

Jaffe, J., Mandelker, G., 1976. The Fisher effect for risky assets: An empirical investigation. Journal of Finance 31, 447-548.

Kapetanios, G., Shin, Y., Snell, A., 2003. Testing for a unit root in the nonlinear STAR framework. Journal of Econometrics 112, 359-79.

Kapetanios, G., Shin, Y., Snell, A., 2006. Testing for cointegration in nonlinear smooth transition error correction models. Econometric Theory 22, 279-303.

Kapetanios, G., Pesaran, M. H., Yamagata, T., 2011. Panels with nonstationary multifactor error structures. Journal of Econometrics 160, 326-348. 
Luintel, K., Paudyal, K., 2006. Are common stocks a hedge against inflation? Journal of Financial Research 29, 1-19.

Luukkonen, R., Saikkonen, P., Teräsvirta, T., 1988. Testing linearity against smooth transition autoregressive models. Biometrika 75, 491-99.

Maki, D., 2010. An alternative procedure to test for cointegration in STAR models. Mathematics and Computers in Simulation 80, 999-1006.

Omay, T., Hasanov M., Ucar N., 2012. Energy consumption and economic growth: Evidence from nonlinear panel cointegration and causality tests. Munich Personal RePEc Archive Paper No. 37653.

Pedroni, P. (1999), "Critical Values for Cointegration Tests in Heterogeneous Panels with Multiple Regressors”, Oxford Bulletin of Economics and Statistics, 61, 653-670.

Pedroni, P., 2000. Fully modified OLS for heterogeneous cointegrated panels. In:Baltagi, B., Kao, C.D. (Eds.), Advances in Econometrics. Non-stationary Panels, Panel Cointegration, and Dynamic Panels. Elsevier, New York, 93-130.

Pedroni, P., 2004. Asymptotic and finite sample properties of pooled time series tests with an application to the PPP hypothesis, Econometric Theory 20, 597-625.

Pesaran, M.H., 2004. General diagnostic tests for cross-section dependence in panels. Working Paper. University of Cambridge, Cambridge.

Pesaran, M.H., 2006, Estimation and Inference in large heterogeneous panels with a multifactor error structure. Econometrica 74, 967-1012.

Pesaran, M.H., 2007. A simple panel unit root test in the presence of cross-section dependence. Journal of Applied Econometrics 22, 265-312.

Phillips, P. C. B., Hansen, B. E., 1990. Statistical inference in instrumental variables regression with I(1) process. Review of Economics Studies 57, 99-125.

Teräsvirta, T., 1994. Specification, estimation, and evaluation of smooth transition autoregressive models. Journal of the American Statistical Association 89, 208-218.

Ucar, N., Omay, T., 2009. Testing for unit root in nonlinear heterogeneous panels. Economics Letters 104, 5-8.

Westerlund, J., 2005. New simple tests for panel cointegration. Econometric Reviews 24, 297316. 


\section{Tables}

Table 1. Cross-section dependence tests

\begin{tabular}{lccc}
\hline Country Group & $\mathrm{CD}_{\mathrm{LM} 1}$ & $\mathrm{CD}_{\mathrm{LM} 2}$ & $\mathrm{CD}_{\mathrm{LM} 3}$ \\
\hline All & 145.108 & $41,467.46$ & 779.482 \\
& $(0.000)$ & $(0.000)$ & $(0.000)$ \\
Developed & 93.126 & $10,403.28$ & 497.38 \\
& $(0.000)$ & $(0.000)$ & $(0.000)$ \\
Emerging & 69.85 & $6,570.66$ & 346.053 \\
& $(0.000)$ & $(0.000)$ & $(0.000)$ \\
Others & 30.939 & $1,586.09$ & 132.307 \\
& $(0.000)$ & $(0.000)$ & $(0.000)$ \\
INF1 H & 96.087 & $12,531.95$ & 478.796 \\
& $(0.000)$ & $(0.000)$ & $(0.000)$ \\
INF1 L & 65.472 & $9,828.53$ & 372.759 \\
& $(0.000)$ & $(0.000)$ & $(0.000)$ \\
INF2 H & 22.16 & $1,625.12$ & 135.703 \\
& $(0.000)$ & $(0.000)$ & $(0.000)$ \\
INF2M & 80.925 & $11,091.70$ & 422.304 \\
& $(0.000)$ & $(0.000)$ & $(0.000)$ \\
INF2 L & 48.799 & $3,418.84$ & 246.675 \\
& $(0.000)$ & $(0.000)$ & $(0.000)$ \\
\hline
\end{tabular}

Notes: $C D_{L M 1}$ denotes Pesaran (2004) cross-section dependence test statistic. $C D_{L M 2}$ and $C D_{L M 3}$ are Breusch and Pagan(1980) LM test statistic and its scaled version, respectively. $\mathrm{P}$-values are given in parentheses. 
Table 2. Unit root tests not taking into account cross-section dependence: IPS test

\begin{tabular}{lrrrrrrrr}
\hline Country Groups & \multicolumn{2}{c}{$\mathrm{CPI}_{\mathrm{i}, \mathrm{t}}$} & \multicolumn{2}{c}{$\Delta \mathrm{CPI}_{\mathrm{i}, \mathrm{t}}$} & \multicolumn{2}{c}{$\mathrm{SP}_{\mathrm{i}, \mathrm{t}}$} & \multicolumn{2}{c}{$\Delta \mathrm{SP}_{\mathrm{i}, \mathrm{t}}$} \\
\hline & \multicolumn{1}{c}{$\mathrm{A}$} & \multicolumn{1}{c}{$\mathrm{B}$} & \multicolumn{1}{c}{$\mathrm{A}$} & \multicolumn{1}{c}{$\mathrm{B}$} & $\mathrm{A}$ & $\mathrm{B}$ & $\mathrm{A}$ & $\mathrm{B}$ \\
\cline { 2 - 9 } All & -0.316 & -1.893 & -9.329 & -10.403 & -0.641 & -1.670 & -10.272 & -9.610 \\
Developed & 0.087 & -1.753 & -10.745 & -10.861 & -1.206 & -1.600 & -10.302 & -10.355 \\
Emerging & -1.208 & -1.927 & -8.220 & -8.626 & -0.378 & -1.871 & -10.751 & -10.928 \\
Others & 0.390 & -0.784 & -8.606 & -8.980 & -0.001 & -1.535 & -9.560 & -9.760 \\
INF1 H & -0.622 & -1.583 & -8.101 & -8.423 & -0.159 & -1.726 & -10.236 & -10.428 \\
INF1 L & -0.009 & -1.707 & -10.557 & -10.798 & -1.124 & -1.613 & -10.308 & -10.378 \\
INF2 H & -1.114 & -1.479 & -7.253 & -7.657 & -0.006 & -1.608 & -10.293 & -10.444 \\
INF2M & -0.369 & -2.065 & -9.301 & -9.456 & -0.737 & -1.837 & -10.367 & -10.517 \\
INF2 L & 0.467 & -1.928 & -11.161 & -11.572 & -1.007 & -1.412 & -10.078 & -10.157 \\
\hline
\end{tabular}

Notes: The figures are Im et al.(2003) $\bar{t}_{N T}$ test statistics. A denotes intercept and B denotes intercept and trend.

Exact critical values of the $\bar{t}_{N T}$ statistic are given in Table 2 of Im et al.(2003). For A IPS test has $5 \%$ critical values for $\mathrm{T}=100$ and $\mathrm{N}$ equals $10,15,20,25$ and 50 are $-1.97,-1.89,-1.84,-1.81$ and -1.73 , respectively. For $\mathrm{B}$, the corresponding figures are $-2.58,-2.51,-2.46,-2.43$ and -2.36 . 
Table 3. Unit root tests taking into account cross-section dependence: CIPS test

\begin{tabular}{lccrrrrrr}
\hline Country Groups & \multicolumn{2}{c}{$\mathrm{CPI}_{\mathrm{i}, \mathrm{t}}$} & \multicolumn{2}{c}{$\Delta \mathrm{CPI}_{\mathrm{i}, \mathrm{t}}$} & \multicolumn{2}{c}{$\mathrm{SP}_{\mathrm{i}, \mathrm{t}}$} & \multicolumn{2}{c}{$\Delta \mathrm{SP}_{\mathrm{i}, \mathrm{t}}$} \\
\hline & $\mathrm{A}$ & $\mathrm{B}$ & $\mathrm{A}$ & $\mathrm{B}$ & $\mathrm{A}$ & $\mathrm{B}$ & $\mathrm{A}$ & $\mathrm{B}$ \\
\cline { 2 - 8 } All & -1.735 & -2.193 & -9.023 & -10.995 & -1.361 & -1.957 & -10.405 & -9.887 \\
Developed & -2.509 & -2.697 & -10.235 & -12.133 & -1.266 & -2.374 & -10.826 & -11.534 \\
Emerging & -1.312 & -2.031 & -7.725 & -8.458 & -2.058 & -2.268 & -11.030 & -11.519 \\
Others & -0.689 & -1.047 & -8.038 & -9.197 & -1.723 & -1.892 & -9.814 & -10.268 \\
INF1 H & -1.169 & -1.800 & -7.528 & -8.299 & -1.816 & -1.932 & -10.298 & -10.841 \\
INF1 L & -1.714 & -2.282 & -10.306 & -11.653 & -1.291 & -1.613 & -10.589 & -11.156 \\
INF2 H & -1.124 & -1.727 & -6.602 & -7.550 & -1.536 & -1.791 & -9.910 & -10.502 \\
INF2M & -2.010 & -2.221 & -9.049 & -10.043 & -1.734 & -2.141 & -10.757 & -11.293 \\
INF2 L & -0.930 & -1.287 & -11.171 & -12.087 & -1.041 & -1.714 & -10.078 & -10.660 \\
\hline
\end{tabular}

Notes: The figures are Pesaran (2007) cross-sectionally augmented IPS (CIPS) test statistics. A denotes intercept and B denotes intercept and trend. Pesaran (2007) gives critical values of CIPS in Tables II (a)-II(c) For A, CIPS test has $5 \%$ critical values for $\mathrm{T}=100$ and $\mathrm{N}$ equals $10,15,20,30$ and 50 are $-2.14,-2.07,-2.07,-2.07$ and -2.08 , respectively. For $\mathrm{B}$, the corresponding figures are $-2.79,-2.60,-2.57,-2.56$ and -2.56 . 
Table 4. Cointegration tests not taking into account cross-section dependence: Pedroni tests

\begin{tabular}{ccccccccc}
\hline Country Groups & \multicolumn{4}{c}{ Panel } & & \multicolumn{3}{c}{ Group } \\
\cline { 2 - 6 } \cline { 8 - 9 } All & $\mathrm{v}$ & rho & $\mathrm{PP}$ & $\mathrm{ADF}$ & & rho & $\mathrm{PP}$ & ADF \\
\cline { 2 - 6 } & -5.945 & 4.72 & 4.275 & 4.178 & & 6.705 & 6.076 & 6.318 \\
Developed & $(0.999)$ & $(0.999)$ & $(0.999)$ & $(0.999)$ & & $(0.999)$ & $(0.999)$ & $(0.999)$ \\
& 0.462 & 0.754 & 0.419 & 0.405 & & 2.636 & 1.871 & 1.833 \\
Emerging & $(0.321)$ & $(0.774)$ & $(0.662)$ & $(0.657)$ & & $(0.995)$ & $(0.969)$ & $(0.966)$ \\
& 0.985 & 0.137 & -0.043 & 0.177 & & 1.632 & 1.049 & 1.332 \\
Others & $(0.162)$ & $(0.554)$ & $(0.482)$ & $(0.570)$ & & $(0.948)$ & $(0.853)$ & $(0.908)$ \\
& 1.768 & -0.510 & -0.525 & -0.218 & & 0.550 & 0.130 & 0.498 \\
INF1 H & $(0.038)$ & $(0.304)$ & $(0.299)$ & $(0.413)$ & & $(0.709)$ & $(0.551)$ & $(0.691)$ \\
& 0.340 & 0.779 & 0.424 & 0.602 & & 2.812 & 2.017 & 2.204 \\
INF1 L & $(0.366)$ & $(0.782)$ & $(0.664)$ & $(0.726)$ & & $(0.997)$ & $(0.978)$ & $(0.986)$ \\
& 0.241 & 0.958 & 0.516 & 0.864 & & 2.678 & 1.857 & 2.248 \\
INF2 H & $(0.404)$ & $(0.831)$ & $(0.697)$ & $(0.806)$ & & $(0.996)$ & $(0.968)$ & $(0.987)$ \\
& 0.298 & 0.749 & 0.854 & 0.958 & & 2.042 & 2.052 & 2.197 \\
INF2M & $(0.382)$ & $(0.773)$ & $(0.803)$ & $(0.831)$ & & $(0.979)$ & $(0.979)$ & $(0.986)$ \\
& 0.569 & 0.307 & -0.403 & -0.267 & & 2.353 & 1.002 & 1.119 \\
INF2 L & $(0.284)$ & $(0.620)$ & $(0.343)$ & $(0.394)$ & & $(0.990)$ & $(0.841)$ & $(0.868)$ \\
& -0.197 & 1.171 & 0.960 & 1.422 & & 2.384 & 2.015 & 2.507 \\
& $(0.578)$ & $(0.879)$ & $(0.831)$ & $(0.922)$ & & $(0.991)$ & $(0.978)$ & $(0.993)$ \\
\hline
\end{tabular}

Notes: The figures Pedroni (1999) test statistics for the null of no cointegration P-values are given in parentheses. The critical values for the panel cointegration tests are based on Pedroni (1999). 
Table 5. Cointegration tests taking into account cross-section dependence

\begin{tabular}{lrrr}
\hline Country Groups & B-CS & UO & OHU \\
\hline All & $-2.446{ }^{*}$ & -1.194 & -1.566 \\
& & $(0.766)$ & $(0.440)$ \\
Developed & $-2.722^{*}$ & -1.284 & -1.687 \\
\multirow{2}{*}{ Emerging } & & $(0.688)$ & $(0.404)$ \\
& $-2.46^{*}$ & -0.988 & -1.317 \\
Others & & $(0.884)$ & $(0.710)$ \\
& -2.053 & -1.257 & -1.69 \\
INF1 H & & $(0.690)$ & $(0.250)$ \\
& -2.069 & -1.116 & -1.436 \\
INF1 L & & $(0.872)$ & $(0.636)$ \\
& $-2.978 *$ & -1.334 & -1.745 \\
INF2 H & & $(0.610)$ & $(0.244)$ \\
& -1.908 & -1.16 & -1.315 \\
INF2M & & $(0.812)$ & $(0.782)$ \\
& $-2.738 *$ & -1.466 & -1.833 \\
INF2 L & & $(0.407)$ & $(0.156)$ \\
& $-2.66 *$ & -1.264 & -1.568 \\
& & $(0.676)$ & $(0.484)$ \\
\hline
\end{tabular}

Notes: B-CS denotes Banerjee and Carrion-Silvestre (2011) common correlated effect estimator to IPS, UO denotes Ucar and Omay (2009) estimator to IPS that uses bootstrap procedure and OHU denotes Omay et al. (2012) nonlinear cointegration test that uses bootstrap procedure. At $5 \%$ significance level Banerjee and Carrion-Silvestre test has critical values for $\mathrm{T}=100$ and $\mathrm{N}$ equals $10,15,20,30$ and 50 are $-2.39,-2.30,-2.24,-2.20$ and 2.15 , respectively. At $10 \%$ significance level the corresponding figures are $2.27,-2,20,-2.16,-2.12$ and -2.08 . For $\mathrm{UO}$ and $\mathrm{OHU} p$-values are shown in parantheses. ${ }^{*}$ shows statistical significance at $5 \%$ level. 
Table 6. FMOLS estimation

\begin{tabular}{cccccccccc}
\hline & \multicolumn{10}{c}{ Country Groups } \\
\hline Cross-Section Dependence & All & Developed & Emerging & Others & INF1 H & INF1 L & INF2 H & INF2M & INF2 L \\
\hline Ignored & 2.44 & 2.64 & 2.74 & 2.29 & 2.51 & 2.37 & 1.70 & 2.66 & 2.66 \\
& $(22.80)$ & $(10.00)$ & $(17.92)$ & $(15.08)$ & $(7.72)$ & $(9.11)$ & $(14.52)$ & $(17.70)$ & $(6.37)$ \\
\hline \multicolumn{1}{l}{ Taken into consideration by using } & & & & & & & & \\
\hline Westerlund & 1.27 & 3.16 & 1.14 & 0.61 & 0.99 & 0.60 & 0.67 & 0.68 & 0.70 \\
& $(5.19)$ & $(3.47)$ & $(0.30)$ & $(5.83)$ & $(0.59)$ & $(8.28)$ & $(2.37)$ & $(2.34)$ & $(5.14)$ \\
Pesaran & 2.50 & 0.64 & 0.90 & 0.21 & 0.02 & 0.43 & 0.46 & 0.38 & 0.74 \\
& $(5.13)$ & $(0.53)$ & $(0.06)$ & $(1.51)$ & $(1.95)$ & $(5.78)$ & $(2.55)$ & $(0.44)$ & $(1.61)$ \\
Oil price & 0.58 & 0.65 & 1.26 & 0.26 & 0.36 & 0.80 & 0.78 & 0.55 & 0.95 \\
& $(0.75)$ & $(2.51)$ & $(0.35)$ & $(1.13)$ & $(2.22)$ & $(1.66)$ & $(1.11)$ & $(3.20)$ & $(0.10)$ \\
\hline
\end{tabular}

Notes: The table shows the estimated long-run elasticity of stock prices with respect to goods prices. Figures in parentheses are the values of the t-statistic associated with the null hypothesis that the coefficient is equal to zero. The t- statistic follows standard normal distribution. 
Table 7. Cross-section dependence tests

\begin{tabular}{lccccccccc}
\hline & & & \multicolumn{1}{c}{ Country Groups } \\
& All & Developed & Emerging & Others & INF1H & INF1 L & INF2 H & INF2M & INF2 L \\
\hline Westerlund & 0.757 & -3.792 & -5.905 & -8.104 & -6.75 & -5.338 & -7.141 & -1.097 & -5.202 \\
& $(0.448)$ & $(0.000)$ & $(0.000)$ & $(0.000)$ & $(0.000)$ & $(0.000)$ & $(0.000)$ & $(0.272)$ & $(0.000)$ \\
Pesaran & 46.083 & 11.803 & 22.364 & 3.003 & 22.701 & 4.121 & 4.307 & 12.217 & -0.804 \\
& $(0.000)$ & $(0.000)$ & $(0.000)$ & $(0.002)$ & $(0.000)$ & $(0.000)$ & $(0.000)$ & $(0.000)$ & $(0.421)$ \\
Oil price & 137.89 & 89.554 & 73.466 & 21.825 & 65.014 & 94.046 & 21.971 & 78.341 & 46.311 \\
& $(0.000)$ & $(0.000)$ & $(0.000)$ & $(0.000)$ & $(0.000)$ & $(0.000)$ & $(0.000)$ & $(0.000)$ & $(0.000)$ \\
\hline
\end{tabular}

Notes: The figures are Pesaran (2004) cross-section dependence test statistic, denoted by $C D_{L M 1}$ in the paper. Pvalues are given in parentheses. 